\title{
Reducing the Internal Stress of Fe-Ni Magnetic Film Using the Electrochemical Method
}

\author{
Yan Wu, Bin Ji and Wei Wang * \\ School of Chemical Engineering and Technology, Tianjin University, Tianjin 300350, China; \\ wuyan2015_@tju.edu.cn (Y.W.); jibin@tju.edu.cn (B.J.) \\ * Correspondence: wangweipaper@tju.edu.cn
}

Citation: Wu, Y.; Ji, B.; Wang, W. Reducing the Internal Stress of Fe-Ni Magnetic Film Using the Electro chemical Method. Processes 2021, 9, 1883. https://doi.org/ $10.3390 /$ pr9111883

Academic Editor: Mingxia Gao

Received: 8 September 2021

Accepted: 17 October 2021

Published: 21 October 2021

Publisher's Note: MDPI stays neutral with regard to jurisdictional claims in published maps and institutional affiliations.

Copyright: (c) 2021 by the authors. Licensee MDPI, Basel, Switzerland. This article is an open access article distributed under the terms and conditions of the Creative Commons Attribution (CC BY) license (https:// creativecommons.org/licenses/by/ $4.0 /)$.

\begin{abstract}
Soft magnetic materials are important functional materials in the electrical engineering, radio, and high-tech fields, but thin and brittle flakes present challenges to the manufacturing industry. In this study, the effect and mechanism of saccharin sodium in reducing the internal stress of Fe-Ni magnetic films were analyzed. The effects of the $\mathrm{pH}$ value, temperature, and the concentration of saccharin sodium on the deposition process of $\mathrm{Fe}-\mathrm{Ni}$ alloys were investigated. The polarization curve of the Fe-Ni alloy deposition process was measured by using a multifunctional electrochemical workstation, and the morphology and crystal structure were measured by a scanning electron microscope (SEM) and X-ray diffraction (XRD). The results show that saccharin sodium significantly reduced the stress of the iron-nickel magnetic film; the mechanism through which the internal stress was reduced is analyzed in this paper. Briefly, the $\mathrm{Fe}^{2+}$ and the amino group of saccharin sodium synthesized a metal complex with positive charge on the surface of the electrode, which prevented the hydrogen ions from approaching the cathode and increased the discharge activation energy of the hydrogen ion, which reduced the hydrogen evolution and improved the internal stress of the coating. This research will help to solve the challenges of producing magnetic film, and promotes the application of new stress-reducing agents.
\end{abstract}

Keywords: internal stress; hydrogen evolution; iron-nickel alloy; saccharin sodium

\section{Introduction}

Soft magnetic materials are important functional materials in the fields of electrical engineering, radio, and high-tech [1-3]. With the advent of information technology and automation, soft magnetic materials have played an irreplaceable role in actual production. Soft magnetic materials have the characteristics of high permeability, low coercivity, high saturation magnetic induction and low residual magnetic induction. Therefore, soft magnetic materials are widely used in the manufacture of stators and rotors for generators and motors, the iron cores of transformers and inductors, magnetic recording heads, magnetic shields, etc. Their application fields include power supply, switching power supply, instrumentation, vehicle electronics, and solar energy, and they play a key role in energy conversion throughout the entire world [4-6]. In our country, with the rapid development of high-tech fields, the demand for soft magnetic materials in various fields is increasing. In addition, in order to manufacture high-frequency, high-efficiency, energysaving motors and other high-end products, China is expanding the application of soft magnetic materials, developing high-performance soft magnetic materials and new processing and manufacturing technologies. It is worth mentioning that in the field of power electronics, the improvement of efficiency will promote the development of smart and flexible transformers, potentially reducing global energy consumption by 20\% [7]. Therefore, an increasing number of researchers are paying attention to magnetic-based passive components (transformers, inductors, and capacitors) and solving the challenges posed by transformers and inductors; both require soft magnetic cores (low coercivity) to achieve high power density. 
Permalloy (iron-nickel alloy) is a soft magnetic alloy with a wide range of applications. It has a very high magnetic permeability, albeit under a weak magnetic field, and the adjustability of its composition is broad; in particular, its magnetic properties can be adjusted by changing the composition and heat treatment process [8-25]. In addition, amorphous and nanocrystalline alloys are currently very advanced materials. The unique nanostructure and extremely thin flakes make the hysteresis loss smaller while still maintaining a considerable magnetic induction saturation [26-31]. However, permalloys, like amorphous and nanocrystalline alloys, have some problems that cannot be ignored, such as their greater brittleness, their difficult processing, and their complicated production processes, which seriously affect the development of soft magnetic materials for different application fields. As is well known, when the internal stress is distributed in the coating, the coating produces stress corrosion. In addition, internal stress increases the porosity and brittleness of the coating. During electroforming, in order to make the electroforming mold easy to separate from the prototype, the internal stress of the electroforming layer should be small, otherwise it will cause blisters, deformation, and difficult peeling. In early research, the coercive force of soft magnetic amorphous alloy FePC was as high as $240 \mathrm{~A} / \mathrm{m}$, which was related to the high internal stress introduced during the quenching process. Moreover, the coercivity of amorphous alloy strips of FeNiPB prepared by melt spin-quenching technology was about $8 \mathrm{~A} / \mathrm{m}[32,33]$. These experimental results proved that eliminating the internal stress can significantly reduce the coercivity of the alloy, thereby reducing the hysteresis loss of the soft magnetic alloy [34-39].

Based on the above background, this study used the electrochemical method to solve the internal stress problem of the iron-nickel alloy, which is widely used in soft magnetic materials. The electrochemical method has obvious advantages. On the one hand, the process of its operation is simple, and its operating condition at room temperature is mild, which is conducive to industrial production and popularization. On the other hand, using electrochemical production methods, the film can be manufactured at fixed points, the size of the film can be small, and the structure and shape are easy to control; in particular its energy consumption is reduced [40-42]. In the electroplating industry, saccharin sodium and others have been found to eliminate cavities, pinholes, and gas marks during nickel plating, but they have different effects in different research systems, and the mechanism of surfactants has not been thoroughly explored [43-47].

In this study, it was found that saccharin sodium can significantly reduce the internal stress of iron-nickel magnetic film under new operating conditions, and we analyzed the mechanism through which saccharin sodium reduces internal stress. This fundamental research will help to promote the development of new stress-reducing agents. It is beneficial to apply saccharin sodium in a wider range to solve the problem of the internal stress of soft magnetic materials, in order to promote the industrial production of magnetic thin films through electrochemical methods.

\section{Experiment}

The Fe-Ni film was plated on a copper sheet by electrodeposition in an electrolyte solution consisting of $0.1 \mathrm{M} \mathrm{FeSO}_{4}$ and $0.1 \mathrm{M} \mathrm{NiSO}_{4}$, and TG23-5 was added in the chemical bath to prevent the $\mathrm{Fe}^{2+}$ from being oxidized. The $\mathrm{pH}$ value was adjusted by adding the dilute sulphuric acid. For the electroplating method of the Fe-Ni magnetic film, firstly, the relationship between the current density and the bright coating was explored by the Hull Cell. Secondly, we used a stepwise method to increase the current density, which was $50 \mathrm{~mA} / \mathrm{cm}^{2}, 75 \mathrm{~mA} / \mathrm{cm}^{2}$, and $100 \mathrm{~mA} / \mathrm{cm}^{2}$. The current density increased every five minutes, and the total electrodeposition time was $15 \mathrm{~min}$. Next, the influence of the $\mathrm{pH}$ value, the temperature, and the concentration of saccharin sodium for the Fe-Ni co-deposition process was explored by measuring the polarization curve, in which the reference electrode iwa a saturated calomel electrode and the scanning speed was $0.5 \mathrm{mV} / \mathrm{s}$. Finally, scanning electron microscope (SEM) and X-ray diffraction (XRD) were used to characterize the morphology and crystal structure of the Fe-Ni magnetic film. 


\section{Result and Discuss}

The $\mathrm{pH}$ value is a very important factor that affects the electrodeposition process. Therefore, the effect of the $\mathrm{pH}$ value on the $\mathrm{Fe}^{2+}$ deposition process was explored first.

Figure 1 indicates the effect of the $\mathrm{pH}$ value on the deposition of $\mathrm{Fe}^{2+}$. It can be clearly seen that the current constantly decreased as the $\mathrm{pH}$ value increased, and the current increased rapidly when the $\mathrm{pH}$ value was 1.2 , because the hydrogen absorption reaction was serious when the $\mathrm{pH}$ value was smaller. The lower $\mathrm{pH}$ value limited the mass transfer process and the ion diffusion was unable to keep up with the electrochemical reaction, so a limiting current appeared when the $\mathrm{pH}$ value was 1.2. The current demonstrated a large fluctuation when the $\mathrm{pH}$ value was 2.5 because some of the $\mathrm{Fe}^{2+}$ may have been oxidized to $\mathrm{Fe}^{3+}$. Therefore, the increase in $\mathrm{pH}$ value inhibits the deposition process of $\mathrm{Fe}^{2+}$, and a $\mathrm{pH}$ value between 1.5 and 2.3 is appropriate in the process of depositing $\mathrm{Fe}^{2+}$.

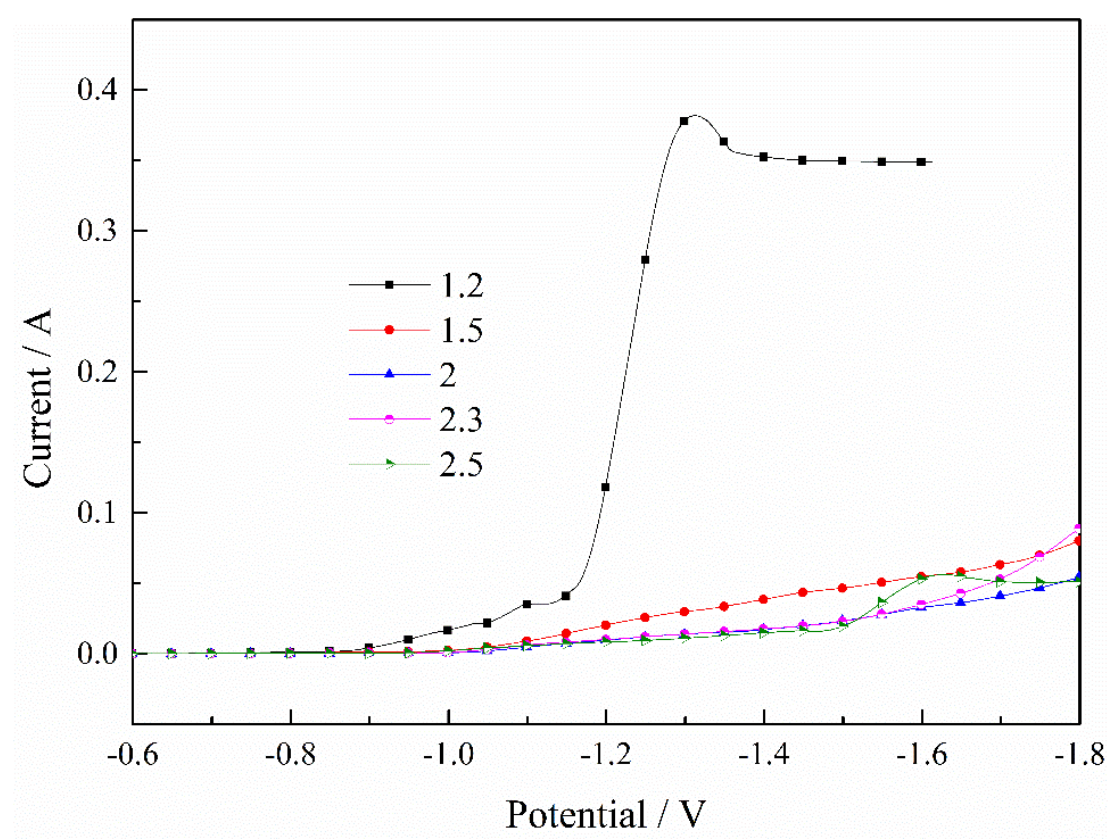

Figure 1. Effect of $\mathrm{pH}$ value on the deposition of $\mathrm{Fe}^{2+} . \mathrm{T}=30^{\circ} \mathrm{C}$.

Figure 2 shows the effect of the $\mathrm{pH}$ value on the deposition of $\mathrm{Ni}^{2+}$. In general, the current decreased gradually as the $\mathrm{pH}$ value increased, which meant that the deposition process of $\mathrm{Ni}^{2+}$ was inhibited with the increase of $\mathrm{pH}$ value. Similarly, the process of deposition was in an unstable state when the $\mathrm{pH}$ value was higher. However, combined with Figure 1, we found that the degree of inhibition on $\mathrm{Ni}^{2+}$ was smaller than the process of $\mathrm{Fe}^{2+}$, so the $\mathrm{H}^{+}$had a greater influence on the deposition process of the $\mathrm{Fe}^{2+}$.

The polarization curves of the Fe-Ni co-deposition process with different $\mathrm{pH}$ valus are indicated in Figure 3. It was found that the currents decreased significantly as the $\mathrm{pH}$ value increased, which was consistent with the deposition of $\mathrm{Fe}^{2+}$. The currents increased rapidly when the $\mathrm{pH}$ value was less than 2 . In the experiment, many bubbles were precipitated on the surface, indicating that the hydrogen evolution reaction was violent at this time. The currents indicated that the co-deposition process was relatively stable when the $\mathrm{pH}$ was greater than 2.3, and there were fewer surface bubbles, indicating that the hydrogen evolution reaction was relatively small.

Figure 4 demonstrates the effect of temperature on the Fe-Ni co-deposition process. We found that as the temperature increased, the currents increased gradually, which meant that increasing the temperature promoted the Fe-Ni co-deposition process. Consequently, the increase of the temperature accelerated the diffusion rate of the $\mathrm{Fe}^{2+}$ and $\mathrm{Ni}^{2+}$, thereby promoting the deposition of the $\mathrm{Fe}^{2+}$ and $\mathrm{Ni}^{2+}$. 


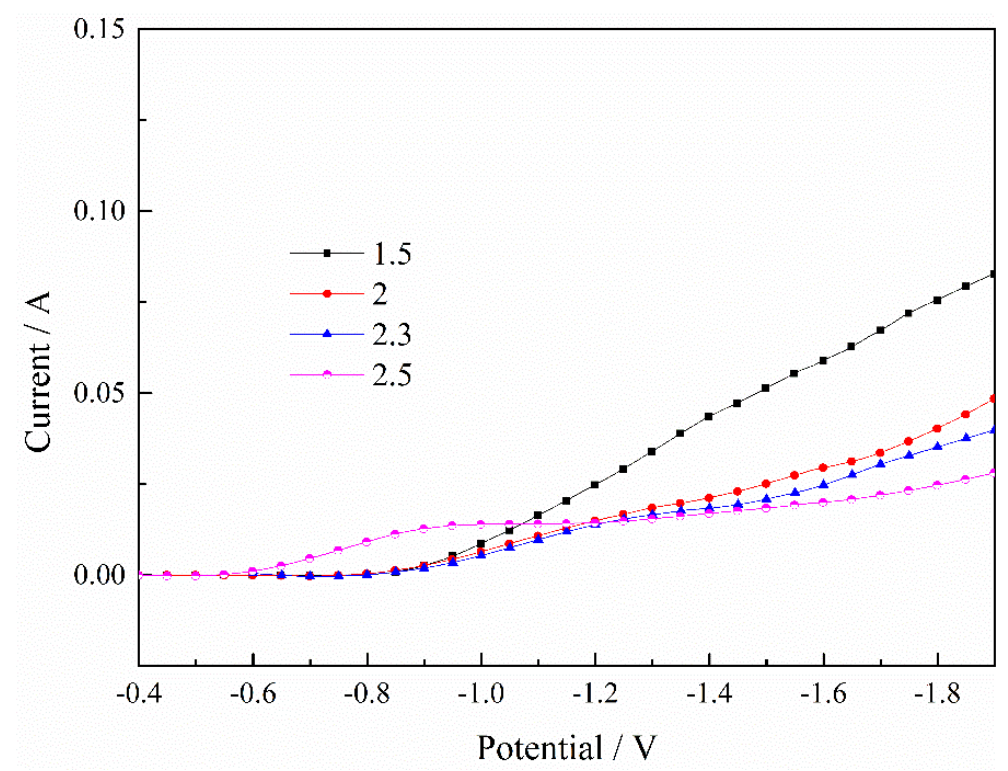

Figure 2. Effect of $\mathrm{pH}$ value on deposition process of $\mathrm{Ni}^{2+} . \mathrm{T}=30^{\circ} \mathrm{C}$.

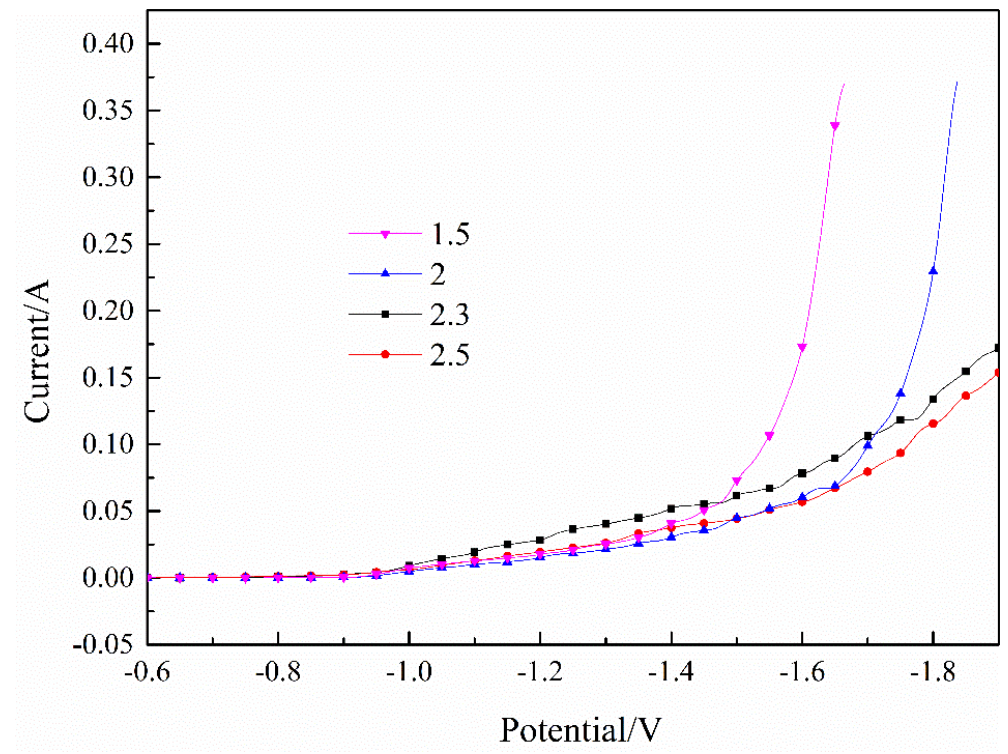

Figure 3. Effect of $\mathrm{pH}$ value on the $\mathrm{Fe}-\mathrm{Ni}$ co-deposition process. $\mathrm{T}=30^{\circ} \mathrm{C}$.

In order to explore the mechanism of saccharin sodium $\left(\mathrm{C}_{7} \mathrm{H}_{5} \mathrm{NO}_{3} \mathrm{SNa}\right)$ clearly, we continued to explore the effect of $\mathrm{C}_{7} \mathrm{H}_{5} \mathrm{NO}_{3} \mathrm{SNa}$ on the electrodeposition process of $\mathrm{Fe}^{2+}$ and $\mathrm{Ni}^{2+}$ separately. Figure 5 shows the polarization curves of the $\mathrm{Fe}^{2+}$ deposition process with $\mathrm{C}_{7} \mathrm{H}_{5} \mathrm{NO}_{3} \mathrm{SNa}$. It was found that as the potential shifted negatively, the current without $\mathrm{C}_{7} \mathrm{H}_{5} \mathrm{NO}_{3} \mathrm{SNa}$ increased significantly, while the current with $\mathrm{C}_{7} \mathrm{H}_{5} \mathrm{NO}_{3} \mathrm{SNa}$ increased less, which indicated that the $\mathrm{C}_{7} \mathrm{H}_{5} \mathrm{NO}_{3} \mathrm{SNa}$ obviously inhibited the deposition process of the $\mathrm{Fe}^{2+}$.

The polarization curve of the $\mathrm{Ni}^{2+}$ deposition process with $\mathrm{C}_{7} \mathrm{H}_{5} \mathrm{NO}_{3} \mathrm{SNa}$ is showed in Figure 6. It indicates that saccharin sodium with moderate potential can improve current efficiency and promote the nucleation process of $\mathrm{Ni}^{2+}$. However, under higher potential conditions, saccharin sodium has an inhibitory effect on nickel deposition. 


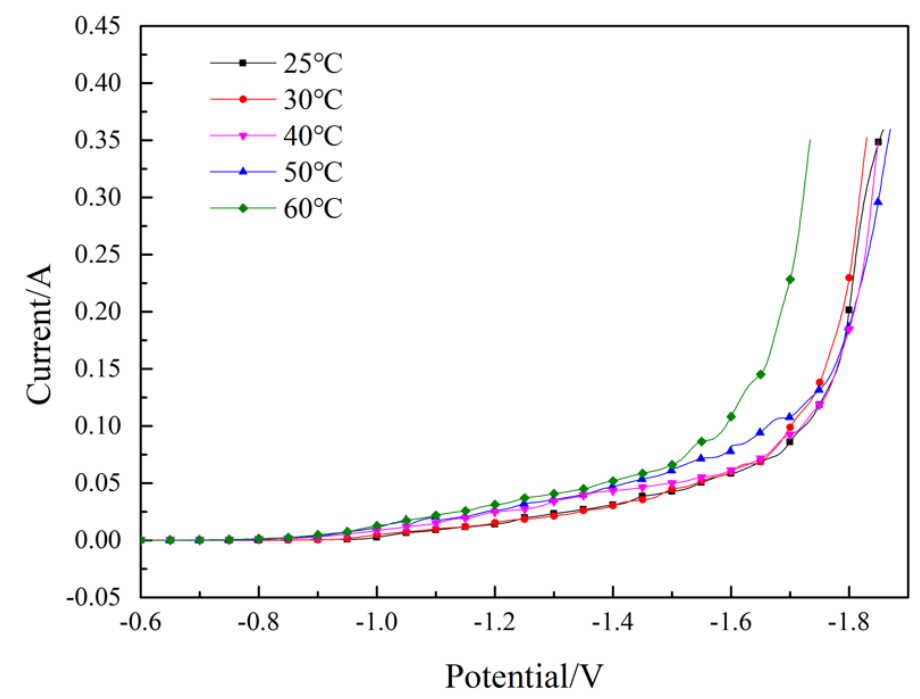

Figure 4. Effect of temperature on the Fe-Ni co-deposition process. $\mathrm{pH}=2$.

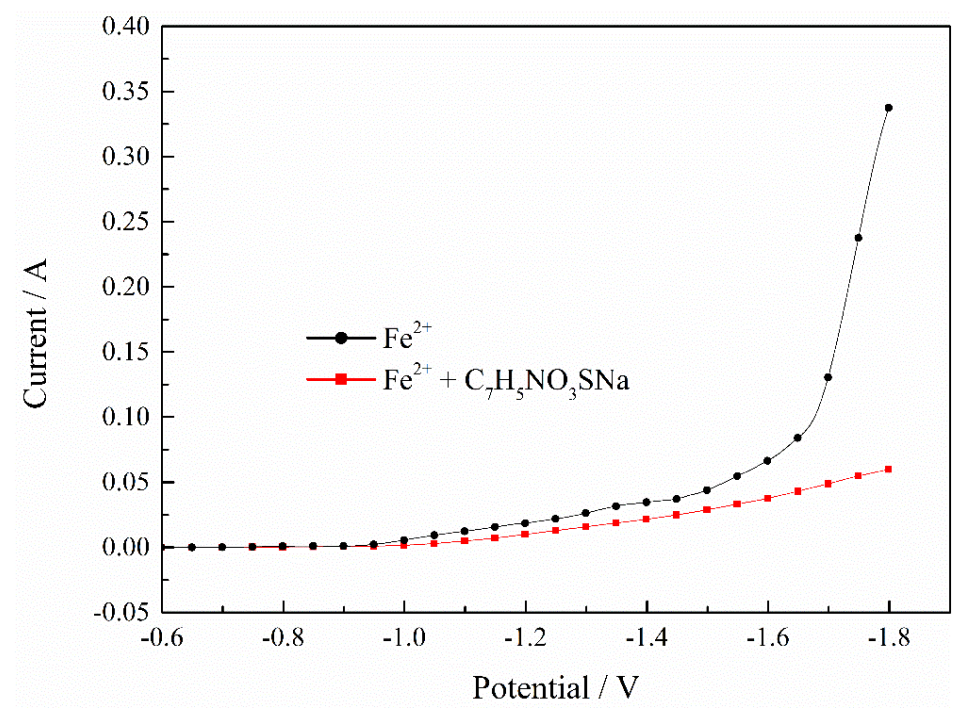

Figure 5. Effect of $\mathrm{C}_{7} \mathrm{H}_{5} \mathrm{NO}_{3} \mathrm{SNa}$ on deposition process of $\mathrm{Fe}^{2+} \cdot \mathrm{pH}=2, \mathrm{~T}=30^{\circ} \mathrm{C}$.

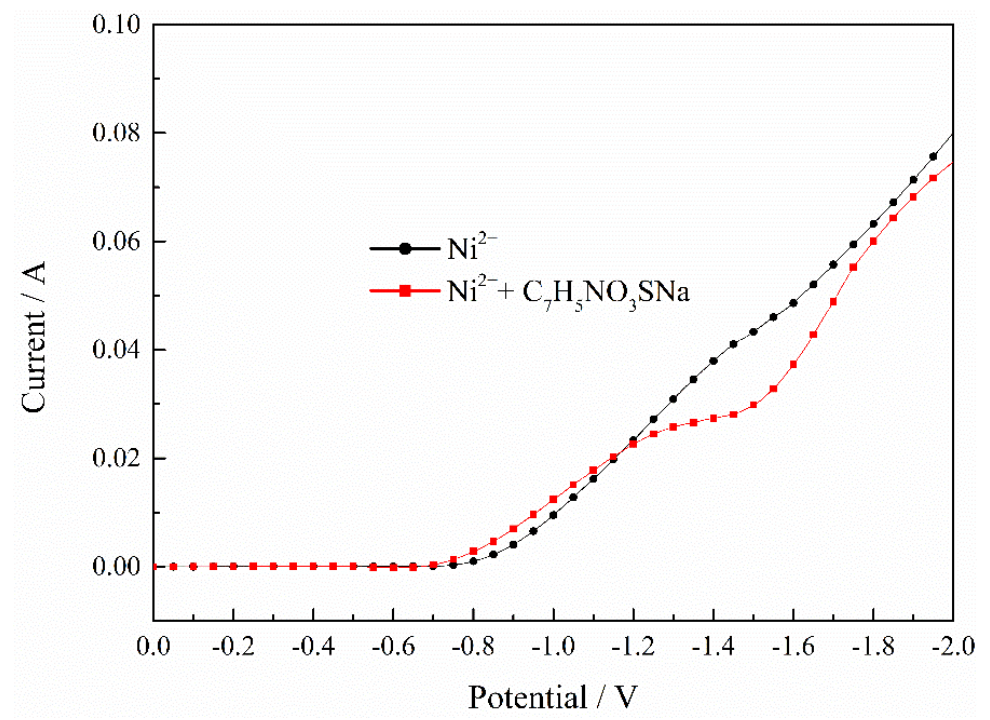

Figure 6. Effect of $\mathrm{C}_{7} \mathrm{H}_{5} \mathrm{NO}_{3} \mathrm{SNa}$ on deposition process of $\mathrm{Ni}^{2+} \cdot \mathrm{pH}=2, \mathrm{~T}=30^{\circ} \mathrm{C}$. 
Figure 7 indicates the effect of $\mathrm{C}_{7} \mathrm{H}_{5} \mathrm{NO}_{3} \mathrm{SNa}$ on the $\mathrm{Fe}-\mathrm{Ni}$ co-deposition process. It can be observed that the currents both increased as the potential shifted negatively, but the current increased slowly when adding the $\mathrm{C}_{7} \mathrm{H}_{5} \mathrm{NO}_{3} \mathrm{SNa}$. The results mean that the adsorption of $\mathrm{C}_{7} \mathrm{H}_{5} \mathrm{NO}_{3} \mathrm{SNa}$ suppressed the $\mathrm{Fe}-\mathrm{Ni}$ co-deposition process significantly.

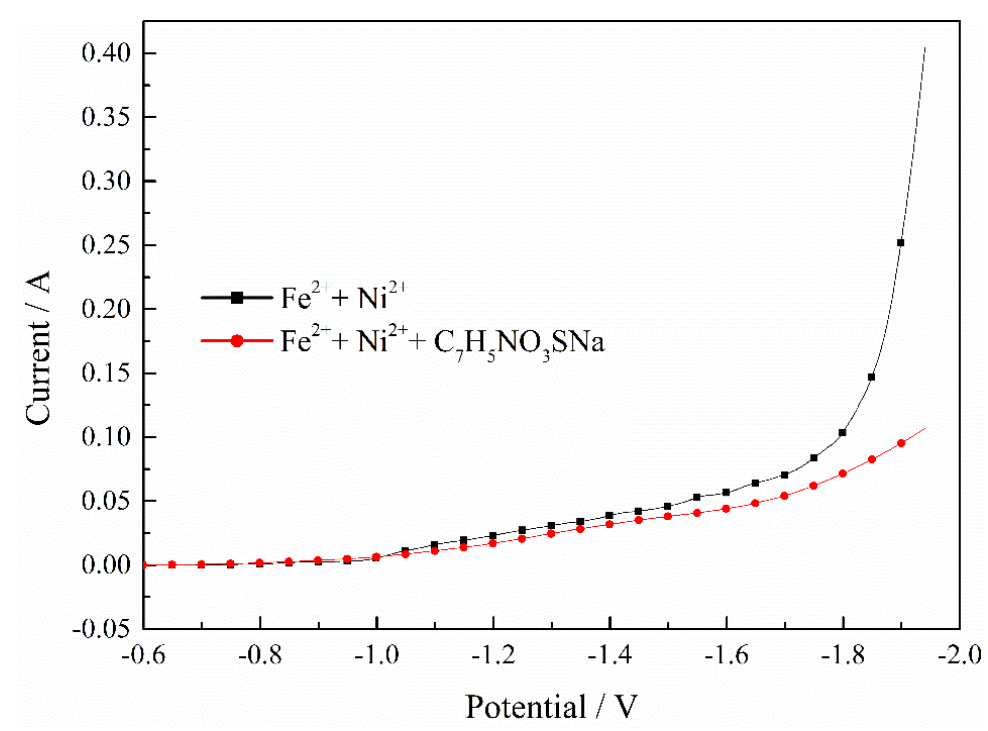

Figure 7. Effect of $\mathrm{C}_{7} \mathrm{H}_{5} \mathrm{NO}_{3} \mathrm{SNa}$ on $\mathrm{Fe}-\mathrm{Ni}$ co-deposition process. $\mathrm{pH}=2, \mathrm{~T}=30^{\circ} \mathrm{C}$.

Figure 8 shows the effect of $\mathrm{C}_{7} \mathrm{H}_{5} \mathrm{NO}_{3} \mathrm{SNa}$ on the rolling angle $(\theta)$ of the Fe-Ni magnetic film. The rolling angle $\theta$ of the magnetic film reflected the magnitude of the internal stress; the concentrations of saccharin sodium were $0 \mathrm{~g} / \mathrm{L}, 1 \mathrm{~g} / \mathrm{L}, 2 \mathrm{~g} / \mathrm{L}$, and $3 \mathrm{~g} / \mathrm{L}$, respectively. Clearly, the rolling angle of the magnetic film decreased as the concentration of $\mathrm{C}_{7} \mathrm{H}_{5} \mathrm{NO}_{3} \mathrm{SNa}$ increased, and when the concentration of $\mathrm{C}_{7} \mathrm{H}_{5} \mathrm{NO}_{3} \mathrm{SNa}$ was $2 \mathrm{~g} / \mathrm{L}$, the rolling angle reached its minimum, and the rolling angle of the magnetic film slightly increased. This was because, as the concentration of saccharin sodium increased, the adsorption capacity increased, the hydrophobic ends of the saccharin sodium were closer to each other and formed micelles when the concentration was increased further, which increased the specific viscosity and hindered the diffusion of the ions. The $\mathrm{C}_{7} \mathrm{H}_{5} \mathrm{NO}_{3} \mathrm{SNa}$ was adsorbed on the surface of the coating, and the amount of $\mathrm{C}_{7} \mathrm{H}_{5} \mathrm{NO}_{3} \mathrm{SNa}$ seriously affected the formation and growth of the crystal nuclei. These results show that under the certain conditions, saccharin sodium can significantly reduce the internal stress of Fe-Ni magnetic film.

Figure 9 presents the effect of saccharin sodium on the surface morphology. It can be clearly seen that the coating without saccharin sodium had coarse grains and severe cracks on its surface (Figure 9a). The surface became flat and the crystal particles were small after adding $2 \mathrm{~g} / \mathrm{L}$ of saccharin sodium (Figure $9 \mathrm{~b}$ ). Furthermore, in the experiment, it was found that without the saccharin sodium, a large amount of hydrogen was precipitated on the cathode's surface. This was because the strong hydrogen evolution reaction reduced the nucleation sites, while the bubbles decreased and the nucleation sites increased when adding the saccharin sodium. Therefore, in order to obtain a better iron-nickel alloy coating, $2 \mathrm{~g} / \mathrm{L}$ of saccharin sodium appropriate.

Figure 10 presents the crystal structure of the iron-nickel alloy with saccharin sodium by XRD. It was found that under the experimental conditions, the saccharin sodium did not affect the structure of the Fe-Ni alloy. Furthermore, the particle size was calculated by XRD and the Scherrer Formula (1). The calculation results showed that the particle size after adding saccharin sodium was about $8.46 \mathrm{~nm}$.

$$
D=\frac{K \gamma}{B \cos \theta}=\frac{0.89 \times 1.54056}{\pi / 180 \times \cos 22.2}=84.64 A=8.46 \mathrm{~nm}
$$




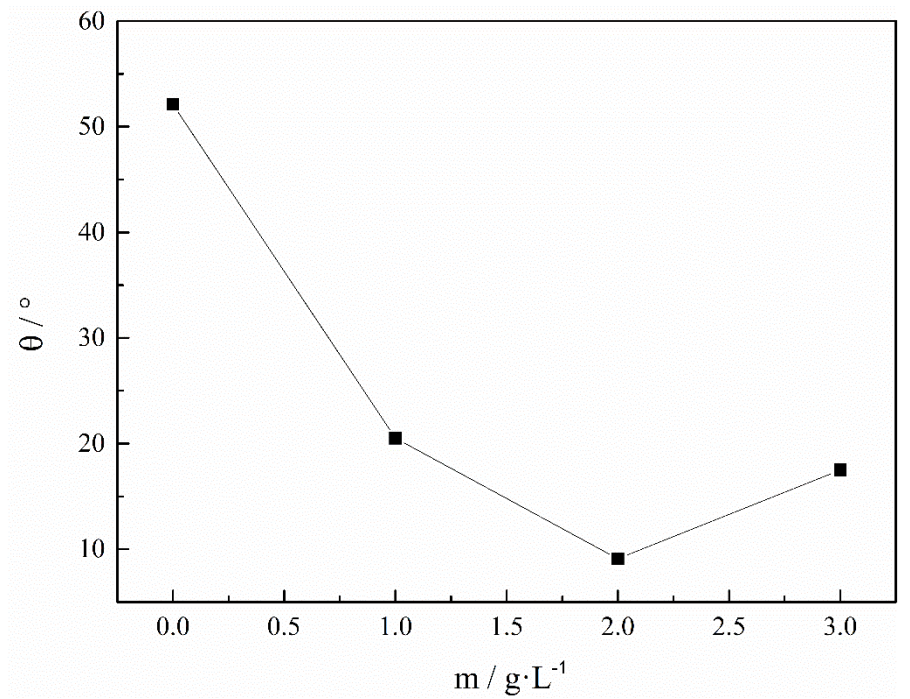

Figure 8. Effect of $\mathrm{C}_{7} \mathrm{H}_{5} \mathrm{NO}_{3} \mathrm{SNa}$ on the rolling angle $(\theta)$ of Fe-Ni magnetic film. $\mathrm{pH}=2,30{ }^{\circ} \mathrm{C}$.
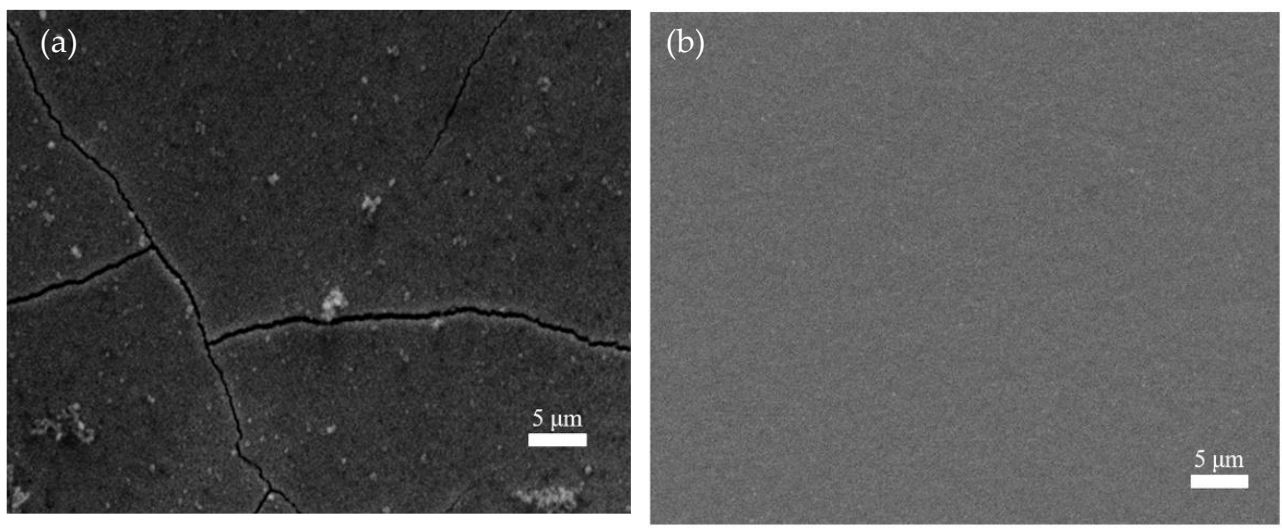

Figure 9. The effect of saccharin sodium on the surface morphology. (a) without saccharin sodium, (b) with saccharin sodium.

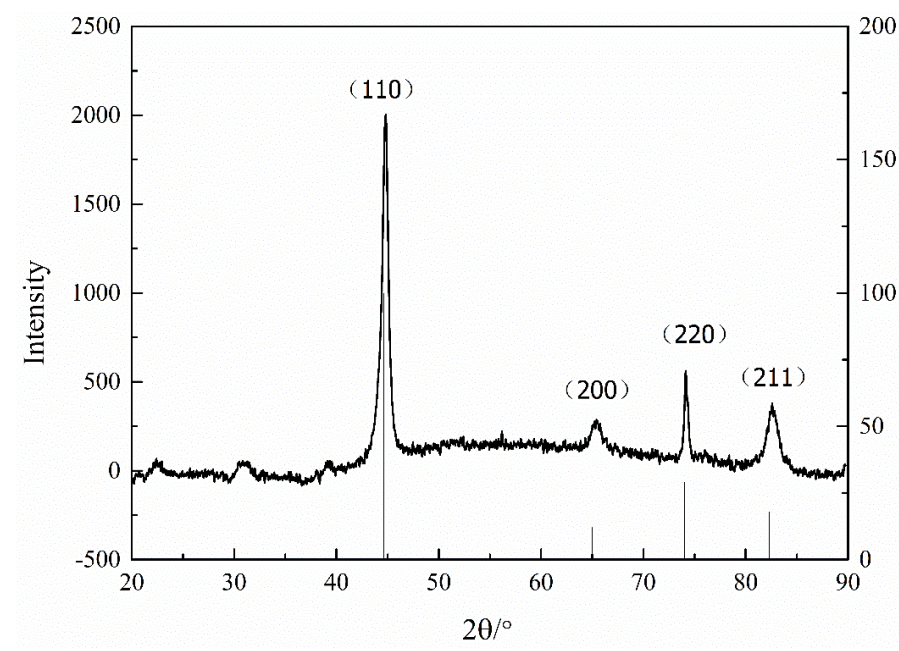

Figure 10. Crystal structure of iron-nickel alloy with saccharin sodium.

$K$ is the Scherrer constant, $D$ is the average thickness of the crystal grain perpendicular to the crystal plane $(\AA), B$ is the measured half-height width or integral width (rad) of the diffraction peak, $\theta$ is the Bragg angle, and $\gamma$ is $1.54056 \AA$, representing the wavelength of the X-ray. 


\section{The Mechanism of Saccharin Sodium}

Saccharin sodium is a sulfamic acid compound with both coordination ability and surface activity. The structure of saccharin sodium is shown in Figure 11. Saccharin sodium contains two hydrophilic groups (carbonyl and amine), one hydrophobic group (benzene ring with strong hydrophobicity) and one sulfinyl. Saccharin sodium is more active in aqueous solution because the ratio of the hydrophobic and hydrophilic. In addition, the presence of sulfinyl groups also determines that saccharin sodium has the characteristics of high polarity, good thermal stability, and good solubility. Therefore, saccharin sodium can be adsorbed directly on the electrode. At this point, the hydrophobic group with less free energy replaces the water molecules and is arranged on the interface. $\mathrm{Fe}^{2+}$ and $\mathrm{H}^{+}$are in a competitive relation on the hydrophilic group of saccharin sodium, but $\mathrm{Fe}^{2+}$ features a lone-pair electron on the $3 \mathrm{~d}$ orbital, making $\mathrm{Fe}^{2+}$ more effective at adsorbing amino groups of saccharin sodium than $\mathrm{H}^{+}$. Furthermore, $\mathrm{Fe}^{2+}$ forms a coordination complex with the amino group of saccharin sodium, which adsorbs on the electrode surface. The positively charged coordination complex prevents $\mathrm{H}^{+}$from approaching the cathode, and increases the activation energy of the hydrogen discharge, thereby reducing the level of hydrogen evolution and improving the internal stress of the coating. In this process, the coordination complexes absorb and discharge at a higher current and make the cathode current evenly distributed. Therefore, saccharin sodium also levels, brightens, and expands the range of current density. In addition, saccharin sodium decreases the amount of hydrogen deposited, so the amount of hydrogen permeation in the coating is reduced, thereby improving the cathode's current efficiency and reducing the fragility of the coating.

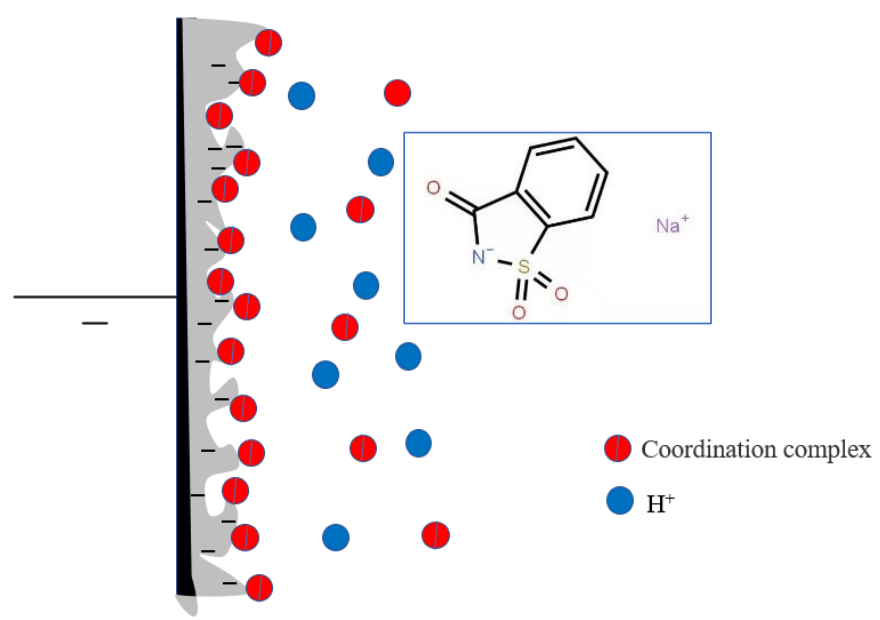

Figure 11. The structure of the complex of saccharin sodium and $\mathrm{Fe}^{2+}$ at the electrode/solution interface.

\section{Conclusions}

In summary, the method of stepwise increasing current density was used, and the results showed that saccharin sodium can significantly reduce the internal stress of ironnickel magnetic films. The mechanism of the saccharin sodium was explored by a series of investigations. Firstly, the electrochemical workstation was used to measure the polarization curves of $\mathrm{Fe}^{2+}, \mathrm{Ni}^{2+}$, and the co-deposition process. The results showed that increases in the $\mathrm{pH}$ value (within a certain range) inhibited the deposition process of $\mathrm{Fe}^{2+}$ and $\mathrm{Ni}^{2+}$. The system was relatively stable when the $\mathrm{pH}$ value was 2 , with a smaller number of surface bubbles indicating that the hydrogen evolution was relatively small. Secondly, the temperature had a greater impact on the iron-nickel co-deposition process. The experiments showed that the increase of temperature promoted the co-deposition process because the diffusion speed of the $\mathrm{Fe}^{2+}$ and $\mathrm{Ni}^{2+}$ are increased. Thirdly, the curling angle $\theta$ of the iron-nickel magnetic film was set to represent the magnitude of the internal stress. The measurement results showed that the curling angle $\theta$ was reduced by $40^{\circ}$ when the 
concentration of the saccharin sodium was $2 \mathrm{~g} / \mathrm{L}$ (compared with no addition of saccharin sodium). The results mean that sodium saccharin can significantly reduce the internal stress of Fe-Ni magnetic film, which in turn reduces the brittleness and expands the application of iron-nickel magnetic film. Finally, we explored the mechanism of the saccharin sodium. This research will help to promote the development of new stress-reducing agents and apply saccharin sodium in a wider range to deal with the manufacturing problems posed by soft magnetic materials.

Author Contributions: Conceptualization, W.W. and Y.W.; methodology, W.W.; software, Y.W.; validation, Y.W., B.J. and W.W.; formal analysis, Y.W.; investigation, Y.W.; resources, B.J.; data curation, Y.W.; writing - original draft preparation, Y.W.; writing-review and editing, Y.W.; visualization, Y.W.; supervision, W.W.; project administration, W.W.; funding acquisition, W.W. All authors have read and agreed to the published version of the manuscript.

Funding: This research received no external funding.

Institutional Review Board Statement: Not applicable.

Informed Consent Statement: Not applicable.

Conflicts of Interest: The authors declare no conflict of interest.

\section{References}

1. Krings, A.; Boglietti, A.; Cavagnino, A.; Sprague, S. Soft magnetic ferrite core blank material conveying device. IEEE Trans. Ind. Electron. 2017, 64, 2405-2414. [CrossRef]

2. Bhattacharya, S. Transforming the transformer. IEEE Spectr. 2017, 54, 38-43. [CrossRef]

3. Krishnamurthy, S. Simplified loss analysis for high speed SiC MOSFET inverter. In Proceedings of the Electronics Conference and Exposition (APEC, IEEE), East Hartford, CT, USA, 12 June 2012; pp. 1414-1417.

4. Kroposki, B. Benefits of Power Electronic Interfaces for Distributed Energy Systems. IEEE Trans. Energy Convers. 2010, 25, 901-908. [CrossRef]

5. Bose, B.K. Global Warming: Energy, Environmental Pollution, and the Impact of Power Electronics. IEEE Ind. Electron. Mag. 2010, 4, 6-17. [CrossRef]

6. Waide, P.; Brunner, C.U. Energy-Efficiency Policy Opportunities for Electric Motor-Driven Systems; International Energy Agency (IEA): IEA Energy Papers: Paris, France, 2011.

7. Popović-Gerber, J. Power Electronics Enabling Efficient Energy Usage: Energy Savings Potential and Technological Challenges. IEEE Trans. Power Electron. 2012, 27, 2338-2353. [CrossRef]

8. Ahn, S.H.; Choi, I.; Park, H.-Y.; Hwang, S.J.; Yoo, S.J.; Cho, E.; Kim, H.-J.; Henkensmeier, D.; Nam, S.W.; Kim, S.-K. Effect of morphology of electrodeposited Ni catalysts on the behavior of bubbles generated during the oxygen evolution reaction in alkaline water electrolysis. Chem. Commun. 2013, 49, 9323-9325. [CrossRef]

9. Lu, X.; Zhao, C. Electrodeposition of hierarchically structured threedimensional nickeleiron electrodes for efficient oxygen evolution at high current densities. Nat. Commun. 2015, 6, 6616. [CrossRef]

10. Vicenzo, A. Structure and mechanical properties of electrodeposited nanocrystalline Ni-Fe alloys. J. Electrochem. Soc. 2013, 160, D570-D577. [CrossRef]

11. Sohrabi, A.; Dolati, A.; Ghorbani, M.; Monfared, A.; Stroeve, P. Nanomechanical properties of functionally graded composite coatings: Electrodeposited nickel dispersions containing silicon micro-and nanoparticles. Mater. Chem. Phys. 2010, 121, 497-505. [CrossRef]

12. Balachandran, R.; Yow, H.; Ong, B.; Tan, K.B.; Anuar, K.; Wong, H. Surface morphology and electrical properties of pulse electrodeposition of NiFe films on copper substrates in ultrasonic field. Int. J. Electrochem. Sci. 2011, 6, 3564-3579.

13. Abdel-Karim, R.; Reda, Y.; Muhammed, M.; El-Raghy, S.; Shoeib, M.; Ahmed, H.J. Electrodeposition and characterization of nanocrystalline Ni-Fe alloys. Nanomaterials 2011, 10, 8. [CrossRef]

14. Liang, D.; Liu, J.; Reuter, K.; Baker-O'Neal, B.; Huang, Q. Electroplating of Fe-Rich NiFe alloys in Sub-50 nm lines. J. Electrochem. Soc. 2014, 161, D301-D308. [CrossRef]

15. Cao, Y.; Wei, G.; Ge, H.; Meng, X. Study on preparation of NiFe films by galvanostatic electrodeposition. Surf. Eng. 2014, 30, 97-101. [CrossRef]

16. Gong, J.; Riemer, S.; Kautzky, M.; Tabakovic, I. Composition gradient, structure, stress, roughness and magnetic properties of 5-500 nm thin NiFe films obtained by electrodeposition. J. Magn. Magn. Mater. 2016, 398, 64-69. [CrossRef]

17. Dragos, O.; Chiriac, H.; Lupu, N.; Grigoras, M.; Tabakovic, I. Anomalous codeposition of fcc NiFe nanowires with 5-55\% Fe and their morphology, crystal structure and magnetic properties. J. Electrochem. Soc. 2016, 163, D83-D94. [CrossRef]

18. Luo, Q.; Peng, M.; Sun, X.; Luo, Y.; Asiri, A.M. Efficient electrochemical water splitting catalyzed by electrodeposited NiFe nanosheets film. Int. J. Hydrogen Energy 2016, 41, 8785-8792. [CrossRef] 
19. Kim, K.H.; Zheng, J.Y.; Shin, W.; Kang, Y.S. Preparation of dendritic NiFe films by electrodeposition for oxygen evolution. RSC Adv. 2012, 2, 4759-4767. [CrossRef]

20. Kuru, H.; Kockar, H.; Alper, M.; Karaagac, O. Growth of binary NieFe films: Characterisations at low and high potential levels. J. Magn. Magn. Mater. 2015, 377, 59-64. [CrossRef]

21. Wei-Su, C.; Yang, W.; Jun-Ming, G.; Feng-Jiao, H. Thermal stability of Ni-Fe alloy foils continuously electrodeposited in a fluorborate bath. Open J. Metal 2012, 2, 18-23.

22. Torabinejad, V.; Rouhaghdam, A.S.; Aliofkhazraei, M.; Allahyarzadeh, M. Electrodeposition of $\mathrm{NieFe}_{\text {and }} \mathrm{NieFe}-\left(\mathrm{nano} \mathrm{Al}_{2} \mathrm{O}_{3}\right)$ multilayer coatings. J. Alloys Compd. 2016, 657, 526-536. [CrossRef]

23. Van Petegem, S.; Zimmermann, J.; Van Swygenhoven, H. Microstructure and deformation mechanisms in nanocrystalline NieFe Part II. In situ testing during X-ray diffraction. Acta Mater. 2013, 61, 5846-5856. [CrossRef]

24. Tabakovic, I.; Inturi, V.; Thurn, J.; Kief, M. Properties of Ni1_xFex $(0.1<x<0.9)$ and Invar $\left(x \frac{1}{4} 0.64\right)$ alloys obtained by electrodeposition. Electrochim. Acta 2010, 55, 6749-6754.

25. Deepthi, K.A.; Balachandran, R.; Ong, B.H.; Tan, K.B.; Wong, H.Y.; Yow, H.K.; Srimala, S. Physical and electrical characteristics of NiFe thin films using ultrasonic assisted pulse electrodeposition. Appl. Surf. Sci. 2016, 360, 519-524. [CrossRef]

26. Ohta, M.; Yoshizawa, Y.J. Recent Progress in Fe-based nanocrystalline soft magnetic alloys and their applications. Phys. D Appl. Phys. 2011, 44, 064004. [CrossRef]

27. Kong, F.; Men, H.; Liu, T.; Shen, B. Research progress and application prospects of Fe-based soft magnetic amorphous/nanocrystalline alloys. J. Appl. Phys. 2012, 111, 07A311. [CrossRef]

28. Fan, X.; Men, H.; Ma, A.; Shen, B. Soft magnetic properties in $\mathrm{Fe}_{84-\mathrm{x}} \mathrm{B}_{10} \mathrm{C}_{6} \mathrm{Cu}_{\mathrm{x}}$ nanocrystalline alloys. J. Magn. Magn. Mater. 2013, 326, 22. [CrossRef]

29. Xiang, Z.; Wang, A.; Zhao, C.; Men, H.; Wang, X.; Chang, C. The solubility of cerium in $\mathrm{La}_{2} \mathrm{Ti}_{2} \mathrm{O}_{7}$ by $\mathrm{DFT}+\mathrm{U}$ calculations J. Alloys Compd. 2015, 622, 1000. [CrossRef]

30. Sharma, P.; Zhang, X.; Zhang, Y.; Makino, A. Competition driven nanocrystallization in high Bs and low coreloss Fe-Si-B-P-Cu soft magnetic alloys. Scr. Mater. 2015, 95, 3. [CrossRef]

31. Jafari, S.; Beitollahi, A.; Yekta, B.E.; Ohkubo, T.; Sky, V.B.; Marsilius, M.; Herzer, G.; Hono, K. Atom probe analysis and magnetic properties of nanocrystalline $\mathrm{Fe}_{84.3} \mathrm{Si}_{4} \mathrm{~B}_{8} \mathrm{P}_{3} \mathrm{Cu}_{0.7}$. J. Alloys Compd. 2015, 674, 136. [CrossRef]

32. Suzuki, K.; Parsons, R.; Zang, B.; Onodera, K.; Kishimoto, H. Copper-free nanocrystalline soft magnetic materials with high saturation magnetization comparable to that of Si steel. Appl. Phys. Lett. 2017, 110, 012407. [CrossRef]

33. Hasegawa, R.; Chien, C.L. Mössbauer and its r.f. sideband effects in iron-rich glassy alloys. Solid State Commun. 1976, 18, 913 [CrossRef]

34. Pathak, S.; Guinard, M.; Vernooij, M.G.C.; Cousin, B.; Wang, Z.; Michler, J.; Philippe, L. Influence of lower current densities on the residual stress and structure of thick nickel electrodeposits. Surf. Coat. Technol. 2011, 205, 3651-3657. [CrossRef]

35. Ortolani, M.; Zanella, C.; Ricardo, C.L.A.; Scardi, P. Elastic grain interaction in electrodeposited nanocomposite nickel matrix coatings. Surf. Coat. Technol. 2012, 206, 2499-2505. [CrossRef]

36. Vazquez, J.A.; Altamirano, L.G.; Pritzker, M.; Luna, R.S.; Cabrera, R.S. Experimental and modeling study of nickel electrodeposition including $\mathrm{H}+$ and water reduction and homogeneous reactions. J. Electrochem. Soc. 2011, 158, D33-D41. [CrossRef]

37. Xie, L.S.; Li, J.S.; Zhang, T.B.; Kou, H.C. Role of milling time and Ni content on dehydrogenation behavior of MgH2/Ni composite. Trans. Nonferr. Met. Soc. China 2017, 27, 569-577. [CrossRef]

38. Dundálek, J.; Šnajdr, I.; Libánský, O.; Vrána, J. Zinc electrodeposition from flowing alkaline zincate solutions: Role of hydrogen evolution reaction. J. Power Sources 2017, 372, 221-226. [CrossRef]

39. Hong, B.; Yu, X.Y.; Jiang, L.X.; Xue, H.T.; Liu, F.Y.; Liu, J.; Liu, Y.X. Hydrogen evolution inhibition with diethylenetriamine modification of activated carbon for a lead-acid battery. RSC Adv. 2014, 4, 33574-33577. [CrossRef]

40. Liu, X.; Evans, P.; Zangari, G. Electrodeposited Co-Fe and Co-Fe-Ni alloy films for magnetic recording write heads. IEEE Trans. Magn. 2000, 36, 3479-3481.

41. Djokic, S.S. Electrodeposition: Theory and Practice; Springer Science \& Business Media: Berlin, Germany, 2010.

42. Boudinar, S.; Benbrahim, N.; Benfedda, B.; Kadri, A.; Chainet, E.; Hamadou, L. Electrodeposition of heterogeneous Mn-Bi thin films from a sulfate-nitrate bath: Nucleation mechanism and morphology. J. Electrochem. Soc. 2014, 161, D227-D234. [CrossRef]

43. Mockute, D.; Butkiene, R.; Nivinskiene, O. Effect of chloride ions on the behavior of saccharin, N-methylsaccharin, and 2-butyne1,4-diol during electrodeposition of nickel from acid electrolytes. Russ. J. Electrochem. 2001, 37, 376-381. [CrossRef]

44. Lukomska, A.; Sobkowski, J. Potential of zero charge of monocrystalline copper electrodes in perchlorate solutions. J. Electroanal. Chem. 2004, 567, 95-102. [CrossRef]

45. Bhandari, A.; Hearne, S.J.; Sheldon, B.W.; Soni, S.K. Microstructural origins of saccharin-induced stress reduction in electrodeposited Ni. J. Electrochem. Soc. 2009, 156, D279-D282. [CrossRef]

46. Lallemand, F.; Ricq, L.; Wery, A.; Bercot, P. The influence of organic additives on the electrodeposition of irongroup metals and binary alloy from sulfate electrolyte. Appl. Surf. Sci. 2004, 228, 326-333. [CrossRef]

47. Hassani, S.; Raeissi, K.; Golozar, M.A. Effects of saccharin on the electrodeposition of Ni-Co nanocrystalline coatings. J. Appl. Electrochem. 2008, 38, 689-694. [CrossRef] 